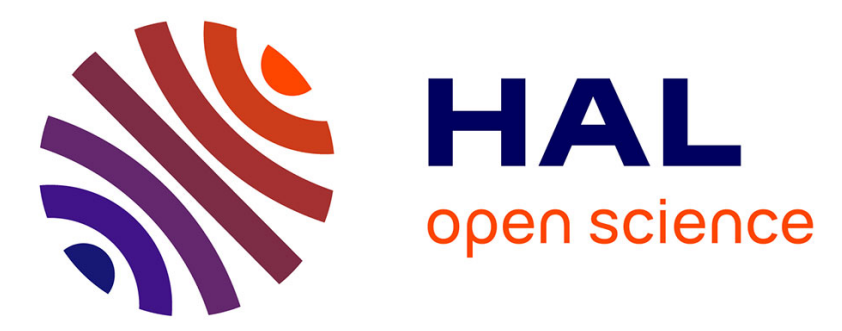

\title{
Micromorphology analysis of sputtered indium tin oxide fabricated with variable ambient combinations
}

\author{
Ştefan Ţălu, Slawomir Kulesza, Miroslaw Bramowicz, Adam M Pringle, \\ Joshua Pearce, M Marikkannan, V Vishnukanthan, J. Mayandi
}

\section{- To cite this version:}

Ştefan Ţălu, Slawomir Kulesza, Miroslaw Bramowicz, Adam M Pringle, Joshua Pearce, et al.. Micromorphology analysis of sputtered indium tin oxide fabricated with variable ambient combinations. Materials Letters, 2018, 220, pp.169-171. 10.1016/j.matlet.2018.03.005 . hal-02111385

\section{HAL Id: hal-02111385 \\ https://hal.science/hal-02111385}

Submitted on 26 Apr 2019

HAL is a multi-disciplinary open access archive for the deposit and dissemination of scientific research documents, whether they are published or not. The documents may come from teaching and research institutions in France or abroad, or from public or private research centers.
L'archive ouverte pluridisciplinaire HAL, est destinée au dépôt et à la diffusion de documents scientifiques de niveau recherche, publiés ou non, émanant des établissements d'enseignement et de recherche français ou étrangers, des laboratoires publics ou privés. 


\title{
Micromorphology analysis of sputtered indium tin oxide fabricated with variable ambient combinations
}

\author{
Ştefan Ţălu ${ }^{1}$, Slawomir Kulesza ${ }^{2}$, Miroslaw Bramowicz ${ }^{3}$, Adam M. Pringle ${ }^{4}$, Joshua M. Pearce ${ }^{4,5}$, \\ M. Marikkannan ${ }^{6}$, V. Vishnukanthan ${ }^{7}$ and J. Mayandi ${ }^{6, *}$
}

${ }^{1}$ Technical University of Cluj-Napoca, Faculty of Mechanical Engineering, Department of AET, Discipline of Descriptive Geometry and Engineering Graphics, 103-105 B-dul Muncii St., ClujNapoca 400641, Cluj, Romania.

${ }^{2}$ University of Warmia and Mazury in Olsztyn, Faculty of Mathematics and Computer Science, Sloneczna 54, 10-710 Olsztyn, Poland.

${ }^{3}$ University of Warmia and Mazury in Olsztyn, Faculty of Technical Sciences, Oczapowskiego 11, 10-719 Olsztyn, Poland.

4 Michigan Technological University, Department of Materials Science \& Engineering Department of Electrical \& Computer Engineering, Michigan Tech Open Sustainability Technology Lab, 601 M\&M Building, 1400 Townsend Drive, Houghton, MI 49931-1295, USA.

${ }^{5}$ Michigan Technological University, Department of Electrical \& Computer Engineering, Michigan Tech Open Sustainability Technology Lab, 601 M\&M Building, 1400 Townsend Drive, Houghton, MI 49931-1295, USA.

${ }^{6}$ Department of Materials Science, School of Chemistry, Madurai Kamaraj University, Madurai 625 021, Tamil Nadu, India.

${ }^{7}$ Department of Physics, Centre for Materials Science and Nanotechnology, University of Oslo,

P.O. Box 1126 Blindern, N-0318 Oslo, Norway

\begin{abstract}
This study experimentally investigates the fractal nature of the 3-D surface morphology of sputtered indium tin oxide (ITO) fabricated with five sets of ambient combinations. The samples were prepared on glass substrates by DC magnetron sputtering using argon, argon with oxygen, argon with oxygen and nitrogen, argon with oxygen and hydrogen and argon with oxygen, nitrogen and hydrogen ambient compositions at room temperature and the films were annealed at $450{ }^{\circ} \mathrm{C}$ in air. The characterization of the films surfaces was carried out by X-ray diffraction (XRD), and atomic force microscopy (AFM). The XRD results indicate that the cubic ITO films form with highly preferable (222) and (400) orientations. The AFM images were analyzed using the Areal Autocorrelation Function (AACF) and pseudo-topothesy K. This analysis revealed that these samples are well described as fractal structures at nanometer scale.
\end{abstract}

Key words: ITO films, ambient combinations, DC magnetron sputtering, AFM, fractal analysis, surface topography

\section{INTRODUCTION}

The superior functional properties of transparent conducting oxides (TCOs) thin films have been extensively studied by various research groups and the films were used as electrodes in optoelectronic devices [1]. Zinc oxide ( $\mathrm{ZnO})$, tin oxide $\left(\mathrm{SnO}_{2}\right)$ and tin doped indium oxide (ITO) are the most commonly used TCOs [2]. Among these TCOs, ITO is a well-established degenerate n- 
type semiconductor with low resistivity and high optical transmission in the visible region of the electromagnetic spectrum [3]. In general, ITO films can be grown by different methods such as solgel [4], chemical solution deposition [5], e-beam evaporation [6], thermal vapour evaporation [7] and DC or RF magnetron sputtering [8]. DC magnetron sputtering is one of the well-known methods for the preparation of ITO films for industrial applications. To obtain the optimal growth conditions in the DC magnetron sputtering various parameters is involved such as substrate temperature, power, and ambient gases [9]. Ambient gases are a significant parameter which alters the growth nature of the ITO films. Usually the ITO films have been deposited using argon, argon with oxygen, hydrogen and nitrogen ambience and the growth nature of the films can be examined by X-ray diffraction (XRD) and atomic force microscopy (AFM) methods [10-12]. Variations in the structural and morphological properties of different ambient deposited ITO films were also studied by various groups. Wan et al. prepared ITO films using argon with oxygen or hydrogen ambient nature and they attained the (222) and (400) plane for argon with oxygen and hydrogen ambient [13]. Likewise the argon with nitrogen ambient deposited films was oriented along the (222) reflection [14]. The orientation of films strongly depends on the ambient compositions in the sputter chambers. Similarly the morphology and surface properties of the different ambient composition developed ITO films can be studied [15]. Recently the microstructure and morphology of the ITO films deposited by RF magnetron sputtering method and the role of argon with oxygen and hydrogen atmosphere was discussed by Nie et al [16]. Jagar et al. studied the morphological properties of the hydrogenated indium oxide films deposited using water vapour or hydrogen by sputtering method [17]. Morphology of the ITO films deposited on glass, mono and multicrystalline silicon substrates have also been investigated and the crystallite size in a three dimensional form and the granular crystallites on glass has been observed for ITO [18]. Based on the literature predictions, microstructure and morphology of the ITO films are the fundamental parameters to decide the device performances.

Thus, the growth nature and physical properties of the materials are key factors to decide the material properties for suitable applications. Korobov, et al. have examined the ITO films grown on glass substrate and the surface coverage, growth model modifications, island coalescence and thickness of the films were briefly discussed [19]. The early growth stages of the ITO films deposited on glass substrates by DC magnetron sputtering method has also been analyzed by Shigesato et al [20]. The 3-D growth, 3-D to 2-D growth transformation of the films was also characterized and analyzed by various research groups [20, 21]. Hence the micro morphological characteristic of the films was examined by AFM technique and it is one of the most significant methods to analyze the surface and fractal structures of the TCO films. The surface roughness of the TCO films was studied using AFM technique and it is difficult to quantitatively describe the morphology of rough surfaces and interfaces of TCO thin films. Mandelbrot et al. proposed an idea using fractal geometry and scaling concepts to examine the rough surface of the TCO films [22]. The fractal dimensionality is one of the traditional techniques to study the complex surface geometries and studied the physical characteristics of the films [22]. The fractal characteristics of different temperatures annealed ITO films were studied by Raoufi, et al. [23] and they have explained the fractal dimension of ITO films with respect to surface morphology. Habitually the nucleation growth and size of the grains altered the surface features of the ITO films.

To build upon this early work, in this study the growth nature of the five sets of ambient combinations deposited ITO films was examined using XRD and AFM methods and the observed morphology and grain sizes of the films were discussed with respect to the ambient compositions. The growth and fractal dimension size dependent surface properties of the ITO films using five set of ambient compositions is studied and the micro morphological properties of the films was examined using AACF and pseudo-topothesy $\mathrm{K}$ analysis. Here, the ITO films deposited using argon (Ar), argon with oxygen $\left(\mathrm{Ar}+\mathrm{O}_{2}\right)$, argon with oxygen and nitrogen $\left(\mathrm{Ar}+\mathrm{O}_{2}+\mathrm{N}_{2}\right)$, argon with oxygen and hydrogen $\left(\mathrm{Ar}+\mathrm{O}_{2}+\mathrm{H}_{2}\right)$ and argon with oxygen, nitrogen and hydrogen $\left(\mathrm{Ar}+\mathrm{O}_{2}+\mathrm{N}_{2}+\mathrm{H}_{2}\right)$ ambient 
combinations were used to sputter ITO targets and deposited on glass substrates and then the films were annealed at $450{ }^{\circ} \mathrm{C}$ for an hour. Both the annealed ITO films microstructure and growth nature with respect to ambient were characterized by XRD and AFM. The obtained AFM images were analyzed using the Areal Autocorrelation Function (AACF) and pseudo-topothesy K and the results are presented with necessary discussions based on the ambient nature.

\section{EXPERIMENTAL}

\subsection{Materials}

$\mathrm{In}_{2} \mathrm{O}_{3} / \mathrm{SnO}_{2}(90 \% / 10 \%)$ target, corning glass (VWR) substrate, argon (Ar), oxygen $\left(\mathrm{O}_{2}\right)$, nitrogen $\left(\mathrm{N}_{2}\right)$, and hydrogen $\left(\mathrm{H}_{2}\right)$, Methanol and DI-Water.

\subsection{Methods}

\subsubsection{ITO Deposition and Annealing}

ITO was deposited using five set of ambient combinations on corning glass (VWR) substrates by DC magnetron sputtering method at room temperature. Before the deposition process, the corning glass substrates were pre-cleaned with methanol and DI water and dried with nitrogen atmosphere. In this present study, five set of ambient were used to deposit the ITO films such as (M1) Ar (180 $\mathrm{sccm})(\mathrm{M} 2)$. Ar (180 sccm) $+\mathrm{O}_{2}(10 \mathrm{sccm})(\mathrm{M} 3)$. Ar $(180 \mathrm{sccm})+\mathrm{O}_{2}(10 \mathrm{sccm})+\mathrm{N}_{2}(10 \mathrm{sccm})$ (M4). Ar (180 sccm ) $+\mathrm{O}_{2}(10 \mathrm{sccm})+\mathrm{H}_{2}(10 \mathrm{sccm})$ and (M5). $\mathrm{Ar}(180 \mathrm{sccm})+\mathrm{O}_{2}(10 \mathrm{sccm})+\mathrm{N}_{2}(10$ $\mathrm{sccm})+\mathrm{H}_{2}(10 \mathrm{sccm})$. Other experimental procedure and conditions was provided in previous works reported in the reference [24]. The as deposited ITO films were annealed at $450{ }^{\circ} \mathrm{C}$ for an hour in air.

\subsubsection{XRD Characterization}

The structural characterization of the set of ITO films were examined using X ray diffraction (XRD - XRD-Scintag-2000 PTS, Scintag Inc., Cupertino, CA, USA) pattern.

\subsubsection{AFM Characterization}

The surface properties of the films were revealed by Veeco Dimension 3000 atomic force microscope (Veeco, Oyster City, NY, USA) operated in tapping mode with Budget Sensors Tap300Al-G cantilevers. The AFM generated sample height, roughness, and surface profile data of five samples and a reference material. Before testing, the AFM was prepared by removing the dustcover, loading a prechecked (optically) cantilever tip and initializing the Nanoscope software. After initialization, the AFM is calibrated, this is done by locating the cantilever tip and adjusting focusing knobs to bring the tip into the cross hairs of the optical lens. Then, the laser is aligned on the photodiode by again rotating focusing knobs to obtain a vertical displacement measuring $\pm 0.1 \mathrm{~V}$, and a sum value of 2.7 (indicating ideal laser contact) in the software. The cantilever is then autotuned, which generates a frequency graph indicating the quality of the cantilever and projected reliability of data to be gathered. Next the sample is placed slightly overhanging on a glass slide and slid into place on the bed of the AFM under the cantilever, which is then lowered (about $1 \mathrm{~cm}$ ) into position and focused (via optical lens) with a track ball. The area of the sample to be measured is the overhanging section. The sample is slightly overhanging to improve visibility of thin layer materials and eliminate interference of any material underneath the sample. A rotating platform was 
then used to easily replace samples reducing the risk of contamination. The scan parameters summarized in Table 1 were followed on the reference material and every experimental sample.

Table 1: AFM scan parameters adjusted for quality data gathering

\begin{tabular}{|l|l|}
\hline Metric & Value \\
\hline Scan size & 2 microns \\
\hline Scan Rate & $0.5549 \mathrm{~Hz}$ \\
\hline Resolution & 512 lines \\
\hline Amplitude set point & $1.1 \mathrm{~V}$ \\
\hline Integral gain & 0.10 \\
\hline Proportional gain & 0.15 \\
\hline
\end{tabular}

After scan parameters were set, the tip was engaged, signifying contact through tapping of the cantilever with the sample. The stepper motor voltage was then adjusted between extension and retraction (the severity of contact between the cantilever and sample surface) to measure as close as possible to $0 \mathrm{~V}$ to allow precise image quality. This process was repeated for each sample and the data file saved. Finally data files measuring height, roughness, and surface profile maps were generated. Autocorrelation Function (AACF) and pseudo-topothesy K analysis was performed using the obtained AFM data.

\subsection{Surface Texture Analysis from AFM}

AFM images are series of equally spaced height samples $z(x, y)$ of the surface under study. Its spatial characteristics are determined using Autocorrelation Function (AACF) [25]:

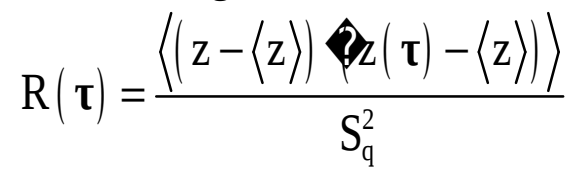

where: $<\ldots>$ denotes the mean value, $S_{q}-$ the root-mean-square (RMS) surface roughness, whereas T - vector of a discrete spatial shift. AACF starts from the unity in the origin, but then monotonically decays with increasing lag (Fig. 1A). Decay length defines the distance at which AACF falls down to 0.2. The ratio of two extreme lengths, i.e. the slowest $\left(\tau_{\mathrm{a} 1}\right)$ and the fastest $\left(\tau_{\mathrm{a} 2}\right)$, defines the anisotropy ratio $S_{\text {tr }}$ that characterizes angular uniformity of the surface texture [26]:

$$
0<\mathrm{S}_{\mathrm{tr}}=\left.\frac{\tau_{\mathrm{a} 1}}{\tau_{\mathrm{a} 2}}\right|_{\mathrm{R}=1}
$$

Surfaces with $S_{\text {tr }}$ above 0.5 are isotropic, i.e. their spatial properties do not vary with the orientation, while those with $S_{\text {tr }}$ below 0.3 are strongly anisotropic. Having the plot of the AACF average grain dimeter can be estimated as well. To this end, the half-widths at the half maxima of the AACF curves along extreme directions are assumed to be the grain radii $R_{a 1}$ and $R_{a 2}$, respectively, the sum of which gives the average grain diameter (see Fig. 1A):

$$
\mathrm{d}_{\text {grain }}=\mathrm{R}_{\mathrm{a} 1}+\mathrm{R}_{\mathrm{a} 2}
$$

Apart from that, however, also various fractal characteristics can be investigated. To this end, the Structure Function (SF) needs to be computed making use of angle-averaged AACF profile [27]:

$$
\mathrm{S}(\tau)=2 \mathrm{~S}_{\mathrm{q}}^{2}(1-\mathrm{R}(\tau))
$$

According to [27], SF profiles follow allometric scaling law as a function of the spatial shift $\mathrm{\tau}$ (see Fig. 1B):

$$
\mathrm{S}(\tau)=\mathrm{K} \tau^{2(2-\mathrm{D})}
$$


where: $\mathrm{D}$ - is the fractal dimension, and $\mathrm{K}$ - pseudo-topothesy. Beyond the threshold $\mathrm{\tau}_{\mathrm{c}}$ referred to as the corner frequency, the allometric scaling breaks down and the SF asymptotically approaches $2 \mathrm{~S}_{\mathrm{q}}{ }^{2}$ value. Our previous studies demonstrated that the corner frequency is found similar to average decay length, and hence to average grain diameter [28,29]. As a quick characterization tool, fractal analysis proved to be useful in studies of morphology and mechanical properties of various surface structures upon heat treatment [30-32], nanomechanical processing [33, 34], in contact with body tissues and fluids [35-38]. Obtained results established a bridge between specific geometry of residual surface and its tribological and physical characteristics [39-41].
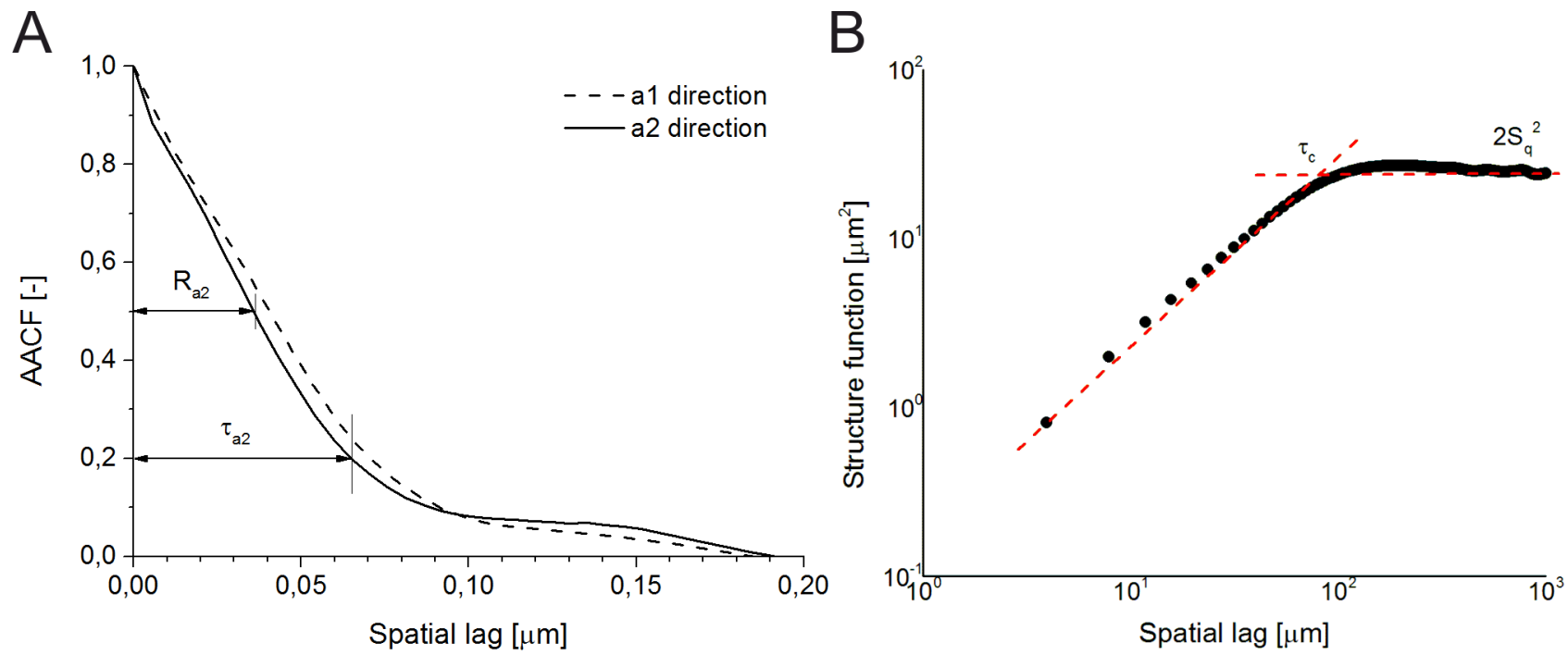

Figure 1. Example plots of functions used for determination of surface texture characteristics: (A) autocorrelation function along extreme directions with the shortest decay length $\tau_{\mathrm{a} 2}$ and grain radius $R_{a 2}$ marked with arrows, (B) profile structure function with the corner frequency $\tau_{c}$ that establishes a threshold beyond which the allometric scaling law vanishes.

\section{Results and Discussion}

\subsection{XRD Analysis}

Fig 2. shows the XRD patterns of ITO thin films deposited on glass substrates and annealed at $450^{\circ} \mathrm{C}$ for an hour. From the observed diffraction results, the major Braggs reflections such as (211), (222), (400) and (622) plane is ascribed for body centered cubic indium oxide structure (060416) and the assigned peaks are supported to other reported ITO XRD results [24]. All the films are polycrystalline nature and preferentially oriented along the (222) and (400) reflections. The detailed analyses of the XRD results were presented elsewhere [1]. From the structural analysis the ambient combinations has altered the preferential orientation of the films and it reflected in the grain sizes of the ITO films as shown in AFM images (Fig. 3). 


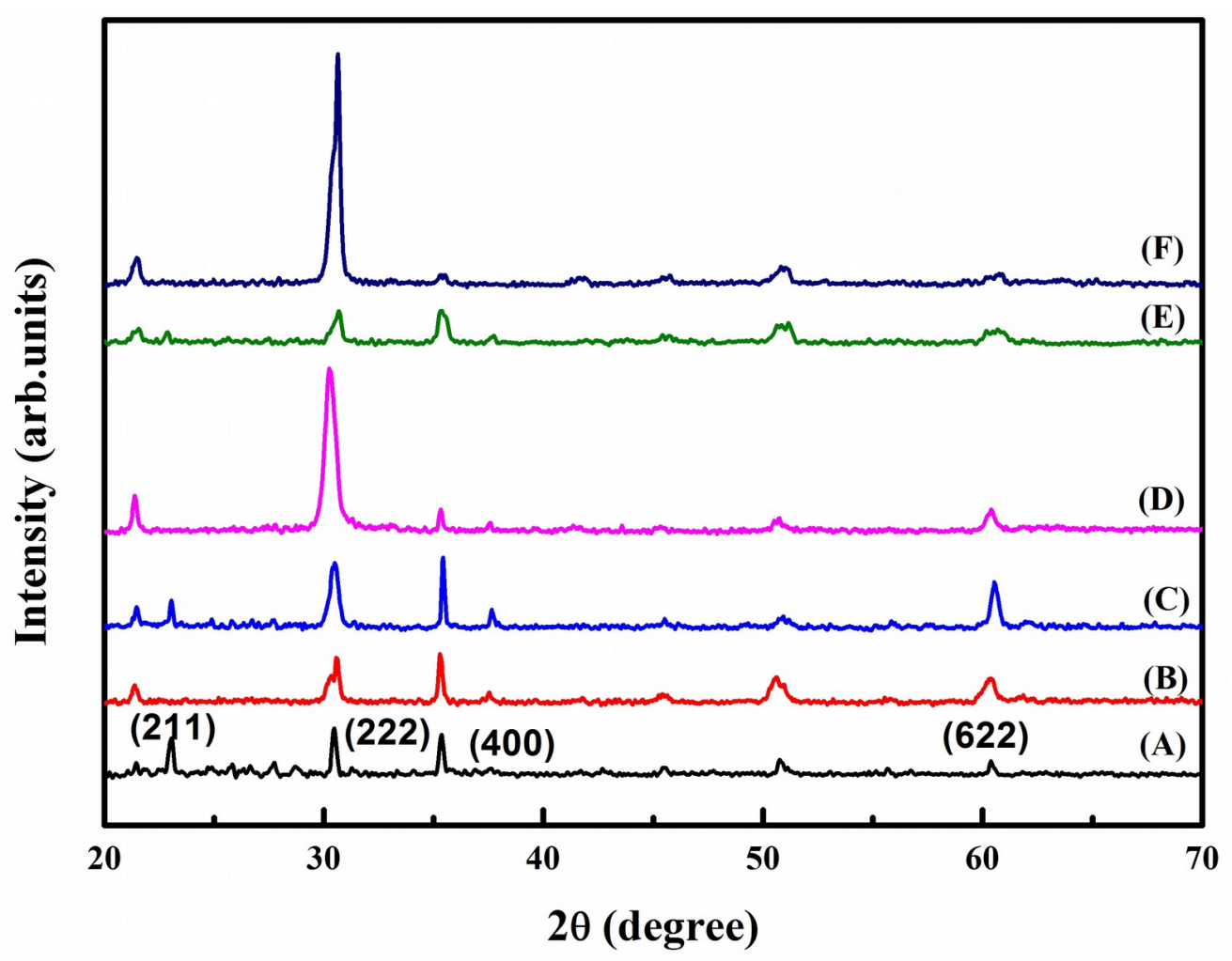

Figure 2. XRD results of the ITO films sputtered under five set of ambient combinations (A) reference sample, (B) M1 sample, (C) M2 sample, (D) M3 sample, (E) M4 sample, (F) M5 sample.

\subsection{Fractal analysis}

AFM images of the samples under investigation are shown in Fig. 3. The images were scanned at 256 equidistant locations with the scan length of $2 \mu \mathrm{m}$. The images exhibit granular structure of the samples, although with different grain size and other spatial features depending on the gas mixture composition. Table 2 summarizes main spatial characteristics of these surfaces determined using both statistical and fractal approaches. When compared, results presented therein allow us to spot interesting similarities, each of which allow us to draw conclusions about the roles the gaseous species play in the deposition process. Note that the following pairs of similar structures can be established: reference and M4, M2 with M3, and M1 with M5. 

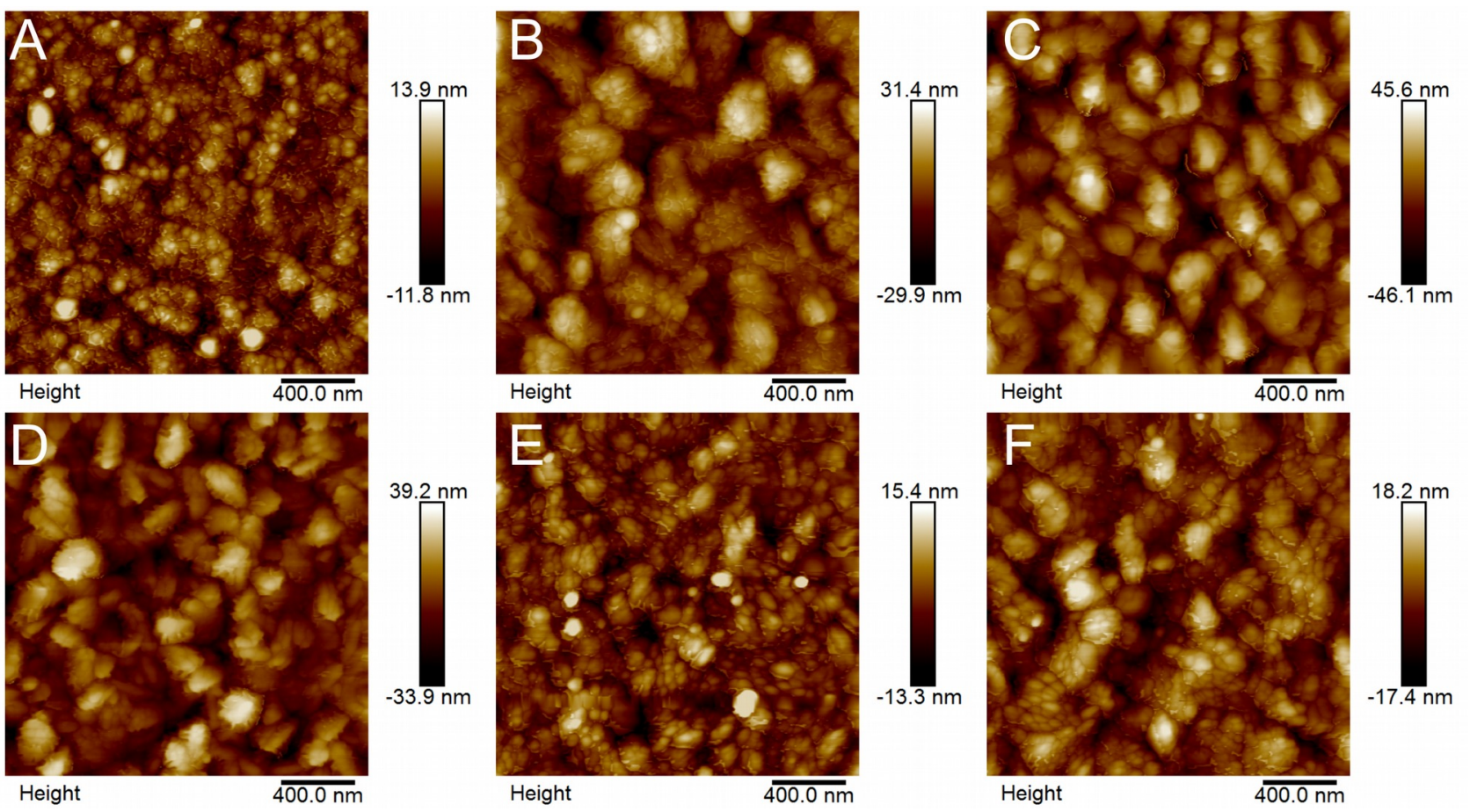

Figure 3. AFM images of the films under study taken with $2 \mu \mathrm{m}$ scan lengths: (A) reference sample, (B) M1 sample, (C) M2 sample, (D) M3 sample, (E) M4 sample, (F) M5 sample.

In general, results presented in Table 2 confirm that the chemical composition of the process atmosphere substantially influences solid structures formed in their presence. The most prominent difference arises when the grain size $d_{\text {grain }}$ is taken into consideration. Note, however, that the grain size corresponds closely to the corner frequency $\tau_{\mathrm{c}}$. As a rule, the grain diameter is found to be around 50-80 per cent larger compared to the corner frequency, which means that the allometric scaling behaviour extends over the surface of the grains solely, and do not go beyond that limit.

Particles grown from the mixture containing pure argon (sample M1) approach $220 \mathrm{~nm}$, that is twice as large as those seen in the reference sample (commercial ITO). Closer inspection reveals that these grains are actually made up of smaller subgrains $70-80 \mathrm{~nm}$ in diameter, similar to those in the reference sample. Unlike the commercial ITO, however, grains in the sample M1 form larger aggregates spread homogeneously over the surface. Argon is well known as a medium that promotes formation of nanocrystalline diamonds from argon-rich gas mixtures in microwave plasma CVD processes due to increasing concentration of free electrons in the deposition zone [42]. Addition of molecular oxygen to the gas mixture (sample M2) diminishes the grain size even more, down to $170 \mathrm{~nm}$. Similar result can be obtained when the same mixture is additionally enriched with molecular nitrogen (sample M3). Obtained structure appears identical to that in sample M2, which means that nitrogen actually exerts no influence on the deposited material, and hence nitrogen behaves as an inert compound of this ternary mixture. Similar mixture in which molecular nitrogen is replaced with hydrogen (sample M4) produces structure nearly identical to that in the reference sample concerning not only the grain size $(120 \mathrm{vs.110} \mathrm{nm})$, but also the remaining descriptors of their surface topography. Such a result demonstrates cooperative effect of oxygen and hydrogen in the process atmosphere, which results in the smallest, nanocrystalline grains. High anisotropy ratio ( $\mathrm{S}_{\text {tr }}$ equal to 0.71 ) is directly related to the fine-grain structure of this film, in which small particles grew into regular shapes and uniformly cover the surface of the sample, but do not form larger clusters. In contrast, the quaternary gas mixture containing all the additives mentioned previously yields a coarse-grain structure composed of large particles (200 $\mathrm{nm}$ in size) and moderate anisotropy (anisotropy ratio equal to 0.58 ). Suppressed high-density nucleation reveals the antagonistic effect of the gaseous species possibly due to their mutual interactions in the gas phase. 
Table 2. Surface texture characteristics of the samples under study: $S_{q}-$ RMS surface roughness, $\mathrm{S}_{\mathrm{tr}}$ - surface anisotropy ratio, D - fractal dimension, $\mathrm{K}$ - pseudo-topothesy, $\tau_{\mathrm{c}}$ - corner frequency, $\mathrm{d}_{\text {grain }}$ - average grain diameter.

\begin{tabular}{|c|c|c|c|c|c|c|c|}
\hline Sample & Description & $\begin{array}{c}\mathbf{S}_{\mathbf{q}} \\
{[\mathbf{n m}]}\end{array}$ & $\mathbf{S}_{\mathbf{t r}}$ & $\mathbf{D}$ & $\mathbf{K}$ & $\begin{array}{c}\boldsymbol{\tau}_{\mathbf{c}} \\
{[\mathbf{n m}]}\end{array}$ & $\begin{array}{c}\mathbf{d}_{\text {grain }} \\
{[\mathbf{n m}]}\end{array}$ \\
\hline Ref & $\begin{array}{c}\text { commercial } \\
\text { ITO }\end{array}$ & 3.51 & 0.72 & 2.42 & 0.173 & 70 & 110 \\
\hline M1 & $\mathrm{Ar}$ & 8.64 & 0.65 & 2.34 & 0.239 & 130 & 220 \\
\hline M2 & $\mathrm{Ar}+\mathrm{O}_{2}$ & 13.3 & 0.62 & 2.31 & 0.572 & 110 & 170 \\
\hline M3 & $\mathrm{Ar}+\mathrm{O}_{2}+\mathrm{N}_{2}$ & 10.6 & 0.70 & 2.30 & 0.354 & 100 & 170 \\
\hline M4 & $\mathrm{Ar}+\mathrm{O}_{2}+\mathrm{H}_{2}$ & 3.88 & 0.71 & 2.39 & 0.142 & 80 & 120 \\
\hline M5 & $\mathrm{Ar}+\mathrm{O}_{2}+\mathrm{N}_{2}+\mathrm{H}_{2}$ & 5.01 & 0.58 & 2.35 & 0.118 & 110 & 200 \\
\hline
\end{tabular}

This improved insight into the impact of the ambient on ITO growth provide a path to better material properties for applications including light emissions such as flat-panel displays and organic or polymer-based electronics [43,44], thin film photovoltaics [45-48], and smart windows to conserve energy [49-50].

\section{CONCLUSIONS}

Furthermore, 3-D surface micromorphology parameters and fractal analysis provide a convenient tool for assessing optimal surface characteristics of five different set of ambient combinations sputtered ITO films on glass substrates. The 3-D surface morphology revealed the fractal geometry of samples at nanometer scale can be quantitatively estimated by the fractal dimension $D$, applied for AFM data. All these morphological parameters can be included in an algorithmically model to characterize the local topography of the 3-D sample surfaces.

\section{REFERENCES}

1. V. A. Dao, H. Choi, J. Heo, H. Park, K. Yoon, Y. Lee, Y. Kim, N. Lakshminarayan, and J. Yi, Curr. Appl. Phys 10, S506 (2010).

2. B. Zhang, N.N. Zhang, J.F. Chen, Y. Hou, S.Yang, J.W. Guo, X.H. Yang, J.H. Zhong, H. F. Wang, P. Hu, H.J. Zhao and H.G. Yang, Scientific Reports 3, 3109 (2013).

3. O.M. Livvik, S. Diplas, A. Romanyuk and A. Ulyashin, J.Appl.Phys. 115, 083705 (2014).

4. H. Cho and Y. H. Yun, Ceram. Int. 27, 615 (2011).

5. J. Lee, S. Lee, G. Li, M. A. Petruska, D. C. Paine, and S. Sun, J.Am.Chem Soc 134, 13410 (2012).

6. M. Himmerlich, M. Koufaki, Ch. Mauder, G. Ecke, V. Cimalla, J. A. Schaefer, E. Aperathitis, and S. Krischok, Surf. Sci. 601, 4082 (2007).

7. V. Vasu and A. Subrahmanyam, Semicond.Sci.Technol 7, 320 (1992).

8. I. Hotovy, J. Pezodlt, M. Kadlecikova, T. Kups, L. Spiess, J. Breza, E. Sakalauskas, R. Goldhahn, and V. Rehacek, Thin Solid Films 518, 4508 (2010).

9. R. BelHadjTahar, T. Ban, Y. Ohya, and Y. Takahashi, J.Appl.Phys 83, 5 (1998).

10. K. Kato, H. Omoto, T. Tomioka, and A. Takamatsu, Thin Solid Films 520, 110 (2011).

11. T.Koida, H. Fujiwara and M. Kondo, Solar Energy Materials \& Solar cells 93, 851 (2009).

12. M. Himmerlich , M. Koufaki , Ch. Mauder , G. Ecke, V. Cimalla, J.A. Schaefer, E. Aperathitis and S. Krischok, Surface Science 601 (2007) 4082-4086. 
13. D. Wan, P. Chen, J. Liang, S. Li and F. Huang, ACS.Appl.Mater.Interfaces.3,4751 (2011).

14. C. Guillen and J. Herrero, J.Appl.Phys.101,073514 (2007).

15. I. Hotovy, J. Pezoldt, M. Kadlecikova, T. Kups, L. Spiess , J. Breza , E. Sakalauskas,

R. Goldhahn, V. Rehacek, Thin Solid Films 518 (2010) 4508-4511.

16. M. Nie, T. Mete and K. Ellmer, J.Appl.Phys. 115,154905 (2014).

17. T. Jagar, Y.E. Romanyuk, S. Nishiwaki, B. Bissig, F. Pianezzi, P. Fuchs, C. Gretener, M.

Dobel and A. N. Tiwari, J.Appl,.Phys.117,205301 (2015).

18. N. Manavizadeh, F. A. Boroumand, E.A. Soleimani, F. Raissi, S. Bagherzadeh, A.

Khodayri and M. Amin Rasouli, Thin Solid Films. 517,2324 (2009).

19. V. Korobov, M. Leibovitch and Y. Shapira, Appl.Phys.Lett.65,2290 (1994).

20. Y. Shigesato, R. Koshi-ishi, T. Kawashima and J. Oshako, Vacuum 59,514 (2000).

21. Y. Sato, M. Taketomo, N. Ito, A. Miyamura and Y. Shigestao, Thin Solid Films.

516,4598 (2008).

22. B.B. Mandelbrot,“ The Fractal Geometry of nature”Freemen Press, San Francisco (1982).

23. D. Raoufi, Physica B. 405, 451 (2010).

24. M. Marikkannan, M. Subramanian, J. Mayandi, M. Tanemura, V. Vishnukanthan, and J. M.

Pearce, AIP Advances 5, 017128 (2015); doi: 10.1063/1.4906566.

25. Nayak P.R. Random process model of rough surfaces, J. of Lubrication Tech., 1971, 93(3): 398407. DOI: $10.1115 / 1.3451608$.

26. Dong W.P., Sullivan P.J., Stout K.J. Comprehensive study of parameters for characterising threedimensional surface topography: IV: Parameters for characterising spatial and hybrid properties. Wear, 1994, 178: 45-60.

27. Thomas A., Thomas T.R. Digital analysis of very small scale surface roughness, Journal of Wave Material Interaction, 1988, 3: 341-350.

28. Ţălu Ş., Bramowicz M., Kulesza S., Shafiekhani A., Ghaderi A., Mashayekhi F., Solaymani S., Microstructure and Tribological Properties of FeNPs@a-C:H Films by Micromorphology Analysis and Fractal Geometry, Ind. Eng. Chem. Res., 2015, 54 (33): 8212-8218. DOI: 10.1021/acs.iecr.5b02449.

29. Bramowicz M., Braic L., Azem F., Kulesza S., Birlik I., Vladescu A., Mechanical properties and fractal analysis of the surface texture of sputtered hydroxyapatite coatings, Applied Surface Science, 2016, 379: 338-346, DOI: 10.1016/j.apsusc.2016.04.077.

30. Szkodo M., Bien A., Antoszkiewicz M. Effect of plasma sprayed and laser re-melted $\mathrm{Al}_{2} \mathrm{O}_{3}$ coatings on hardness and wear properties of stainless steel, Ceramics International 2016, 42: 1127511284.

31. Szkodo M., Bień A., Influence of laser processing of the low alloy medium carbon structural steel on the development of the fatigue crack, Surface \& Coatings Technology, 2016, 296: 117-123.

32. Ţălu Ş., Bramowicz M., Kulesza S., Solaymani S., Ghaderi A., Dejam L., Elahi S.M., Boochani A. Microstructure and Micromorphology of ZnO Thin Films: Case Study on Al Doping and Annealing Effects, Superlattices and Microstructures, 2016, 93: 109-121, DOI: 10.1016/j.spmi.2016.03.003.

33. Ţălu Ş., Bramowicz M., Kulesza S., Solaymani S., Shafikhani A., Ghaderi A., Ahmadirad M. Gold Nanoparticles Embedded in Carbon Film: Micromorphology Analysis, Journal of Industrial and Engineering Chemistry, 2016, 35: 158-166, DOI: 10.1016/j.jiec.2015.12.029.

34. Vranceanu D.M., Cotrut C.M., Bramowicz M., Titorencu I., Kulesza S., Kiss A., Berbecaru A., Pruna V., Branzei M., Vladescu A. Osseointegration of sputtered SiC-added hydroxyapatite for orthopaedic applications, Ceramics International, 2015, 42: 10085-10093, DOI: 10.1016/j.ceramint.2016.03.114.

35. Ţălu Ş., Bramowicz M., Kulesza S., Lainović T., Vilotić M., Blažić L. Influence of the artificial saliva storage on 3-D surface texture characteristics of contemporary dental nanocomposites, Journal of Microscopy, 2016, 264: 198-206, DOI: 10.1111/jmi.12432. 
36. Kulesza S., Bramowicz M., Czaja P., Jabłoński R., Kropiwnicki J., Charkiewicz M. Application of Atomic Force Microscopy for studies of fractal and functionals properties of biomaterials, Acta Physica Polonica A, 2016, 130: 1013-1015. DOI: 10.12693/APhysPolA.130.

37. Ţălu Ş., Bramowicz M., Kulesza S., Ghaderi A., Dalouji V., Solaymani S., Khalaj Z. Microstructure and Micromorphology of $\mathrm{Cu} / \mathrm{Co}$ Nanoparticles: Surface Texture Analysis, Electronic Materials Letters, 2016, 12: 580-588, DOI: 10.1007/s13391-016-6036-y.

38. Ţălu Ş., Bramowicz M., Kulesza S., Shafiekhani A., Rahmati M., Ghaderi A., Ahmadirad M., Solaymani, S. Microstructure of nickel nanoparticles embedded in carbon films: case study on annealing effect by micromorphology analysis, Surface and Interface Analysis, 2016. DOI: 10.1002/sia.6074.

39. Ţălu Ş., Micro and nanoscale characterization of three dimensional surfaces. Basics and applications. Napoca Star Publishing House, Cluj-Napoca, Romania, 2015.

40. Ţălu Ş., Ghazai A.J., Stach S., Hassan A., Hassan Z., Ţălu M., Characterization of surface roughness of Pt Schottky contacts on quaternary $\mathrm{n}-\mathrm{Al}_{0.08} \mathrm{In}_{0.08} \mathrm{Ga}_{0.84} \mathrm{~N}$ thin film assessed by atomic force microscopy and fractal analysis, Journal of Materials Science: Materials in Electronics 25(1) (2014) 466-477.

41. Ţălu Ş., Stach S., Zaharieva J., Milanova M., Todorovsky D., Giovanzana S. Surface roughness characterization of poly (methylmethacrylate) films with immobilized Eu(III) $\beta$-Diketonates by fractal analysis. Int. J. Polym. Anal. Ch. 2014, 19(5): 404-421.

42. Ţălu Ş., Bramowicz M., Kulesza S., Ghaderi A., Dalouji V., Solaymani S., Kenari M.F, Ghoranneviss M. Fractal features and surface Micromorphology of diamond nanocrystals, Journal of Microscopy, 2016, 264: 143-152. DOI: 10.1111/jmi.12422.

43. Kim, H., Gilmore, C.M., Pique, A., Horwitz, J.S., Mattoussi, H., Murata, H., Kafafi, Z.H. and Chrisey, D.B., 1999. Electrical, optical, and structural properties of indium-tin-oxide thin films for organic light-emitting devices. Journal of Applied Physics, 86(11),6451-6461. doi:10.1063/1.371708.

44. Kim, H., Pique, A., Horwitz, J.S., Mattoussi, H., Murata, H., Kafafi, Z.H. and Chrisey, D.B., 1999. Indium tin oxide thin films for organic light-emitting devices. Applied Physics Letters, 74(23), 3444-3446.

45. Lozano, A.E., Abajo, J.D., de la Campa, J.G., Guillén, C., Herrero, J. and Gutierrez, M.T., 2007. Thin-film polyimide/indium tin oxide composites for photovoltaic applications. Journal of Applied Polymer Science, 103(6), 3491-3497.

46. Fleischer, K., Arca, E. and Shvets, I.V., 2012. Improving solar cell efficiency with optically optimised TCO layers. Solar Energy Materials and Solar Cells, 101, 262-269.

47. Gwamuri, J., Marikkannan, M., Mayandi, J., Bowen, P.K. and Pearce, J.M., 2016. Influence of oxygen concentration on the performance of ultra-thin RF magnetron sputter deposited indium tin oxide films as a top electrode for photovoltaic devices. Materials, 9(1), 63; doi:10.3390/ma9010063 48. Gwamuri, J., Vora, A., Mayandi, J., Güney, D.Ö., Bergstrom, P.L. and Pearce, J.M., 2016. A new method of preparing highly conductive ultra-thin indium tin oxide for plasmonic-enhanced thin film solar photovoltaic devices. Solar Energy Materials and Solar Cells, 149, 250-257. Doi: 10.1016/j.solmat.2016.01.028

49. Granqvist, C.G. and Hultåker, A., 2002. Transparent and conducting ITO films: new developments and applications. Thin Solid Films, 411(1), 1-5.

50. Azens, A. and Granqvist, C., 2003. Electrochromic smart windows: energy efficiency and device aspects. Journal of Solid State Electrochemistry, 7(2), 64-68. 